\title{
Comparative Sensitivity and Specificity of Various Serological Tests for Detection of Brucellosis in Small Ruminants
}

\author{
R.R. Padher*, J.B. Nayak, M.N. Brahmbhatt and R.A. Mathakiya \\ Department of Veterinary Public Health, College of Veterinary Science and Animal Husbandry, \\ Anand Agricultural University, Anand, 388001, Gujarat, India \\ *Corresponding author
}

\section{A B S T R A C T}

Brucellosis is a zoonosis known to be a major public health hazard of great economic importance globally. The present study was taken up to ascertain the seroprevalence of brucellosis in goats, sheep, and humans of Anand, districts of the Central Gujarat region. A total of 200 serum samples were collected from the goat and sheep of Anand district and subjected to different serological test i.e., Rose Bengal Plate test (RBPT), Standard Tube Agglutination Test (STAT) and Indirect ELISA to detect the Brucella antibody and also compared in terms of their sensitivity and specificity. A total 200 sera sample including 100 from goats and 100 from sheep collected from the Anand district. Among 200 sera samples of sheep and goats, $94(47.00 \%)$ samples were found to be positive. 93 sera samples were positive by I-ELISA, 27 by RBPT while 16 by STAT. One RBPT positive goat serum sample was found to be negative by I-ELISA. Fifty six goat sera samples were found to be sero-positive, out of which 55 samples were found to be positive by I-ELISA while 16 by RBPT and 10 by STAT. Among 38 sera samples of sheep found to be positive by I-ELISA while 11 by RBPT and 6 by STAT. In case of goats, the sensitivity of RBPT and STAT was 27.27 and 18.18 per cent while specificity was 97.82 and 100 per cent, respectively. An overall agreement of RBPT and STAT with I-ELISA was 66.00 and 55.00 per cent, respectively. Thus, sensitivity of RBPT was more than STAT but specificity of RBPT and STAT was somewhat similar. In case of sheep, the sensitivity of RBPT and STAT was 28.95 and 15.78 per cent while specificity was 100 per cent for both test. An overall agreement of RBPT and STAT with I-ELISA was 73.00 and 68.00 per cent, respectively. Thus, sensitivity of RBPT was more than STAT but specificity of RBPT and STAT was similar.

\section{Introduction}

Brucellosis is one of the world's major diseases. It is neglected zoonoses (WHO, 2009) largely due to lack of public awareness and especially in pastoral and mixed croplivestock farming systems (McDermott and Arimi, 2002). Serological evidence suggest that brucellosis is highly endemic in the most part of India (Raju et al., 2004; Thavamathi,
2006; Valarmathy et al., 2007 and Singh et al., 2013). Polding (1942) first reported the isolation of $B$. melitensis from goat in India. Subsequently, B. abortus was isolated from cases of abortion in Haryana (Mathur, 1967).In small ruminants, most clinical infection is manifested as fertility-related issues. However, the most common symptoms 
are usually abortions during the trimester including retained placenta, weak offspring and metritis which may result in temporary infertility. Others include drop in milk production due to the infection of the udder. Rams experience orchitis and epididymitis. In addition, animals with polyarthritis have been observed in endemic flocks (Radostits, Gay, Hinchcliff, \& Constable, 2006). Seropravelance studies from the backbone of epidemiology investigation and are used to identify herd infected with Brucella (Renukaradhya et al., 2002). The serological tests include Rose Bengal Plate Test, Complement Fixation Test, Serum Agglutination Test and Enzyme Linked Immunosorbent Assay (ELISA) test (Pal, 2007). RBPT test has proven useful as a herd screening test and is highly sensitive (MacMillan, 1990).

\section{Materials and Methods}

The study was conducted to detect Brucella antibodies for 200 sera samples comprising goat sera (100) and sheep sera (100) collected from various areas of Anand district, under aseptic precautions. These sera samples were tested for Brucella antibodies using RBPT, STAT, and I-ELISA for detecting Brucella antibodies from serum. Rose Bengal Plate Test was carried out by using rose Bengal plate test antigen. Using B.abortus agglutinating antigen carried out standard tube agglutination test. Both antigens were procured from Indian Veterinary Research Institute, Izatnagar. Indirect enzyme linked immunosorbent assay was carried out by using the smooth lipopolysaccharide (S-LPS) I-ELISA kits (for sheep and goat sera) procured from ICAR-National Institute of Veterinary Epidemiology and Disease Informatics (ICAR-NIVEDI) Bengaluru. The samples were collected in vacutainer with serum clot activator and transported to the departmental P. G. research laboratory on icebox for further processing and serological analysis. The vacutainer was kept in upright position at room temperature for about $2 \mathrm{hr}$. Then the tubes were centrifuged at $3000 \mathrm{rpm}$ for 10 minutes to facilitate separation of serum, which was collected in a screw capped plastic vials. The sera were stored at $-20^{\circ} \mathrm{C}$ till subjected to I-ELISA.

\section{Results and Discussion}

\section{Overall seroprevalence of brucellosis in small ruminants}

Among 200 sera samples of sheep and goat overall, $94(47.00 \%)$ samples were found to be positive for brucellosis. 27 (13.50\%) sera samples were positive by RBPT while 16 $(8.00 \%)$ by STAT and $93(46.50 \%)$ by IELISA, One RBPT positive goat serum sample were found to be negative by IELISA. The seropositivity was the highest by I-ELISA, intermediate by RBPT and lowest by STAT (Table $1 \& 2$, Fig. 1)

\section{Comparative efficacy of serological tests}

\section{Comparison of I-ELISA as compare to RBPT and STAT}

In the present study, overall seropositivity for Brucella antibodies was detected by RBPT, STAT and I-ELISA to compare their efficacy. Total 200 serum samples comprising of 100 from goats and 100 from sheep, were tested for the presence of Brucella antibodies by RBPT, STAT and I-ELISA. Overall, comparison to $46.50 \%$ of seropositivity in IELISA, $13.50 \%$ and $8.00 \%$ of the samples were found seropositive by RBPT and STAT, respectively. In goat, comparison to $55.00 \%$ of seropositivity in I-ELISA, $16.00 \%$ and $10.00 \%$ of the samples were found seropositive by RBPT and STAT, respectively while in sheep comparison to $38.00 \%$ of seropositivity in I-ELISA, $11.00 \%$ 
and $6.00 \%$ of the samples were found seropositive by RBPT and STAT, respectively. Thus, I-ELISA detected highest seroprevalence than RBPT and STAT and RBPT detected more seroprevalence than STAT in both goats and sheep.

\section{Comparison of sensitivity and specificity of I-ELISA, RBPT and STAT}

Overall the sensitivity of RBPT and STAT was $27.95 \%$ and $17.20 \%$, respectively, considering I-ELISA as a gold standard test while specificity was $99.06 \%$ and $100 \%$, respectively. An overall agreement of RBPT and STAT with I-ELISA was $66.00 \%$ and $61.50 \%$, respectively (Table 4.8 and Figure 4.13). Thus, sensitivity of RBPT was more than STAT but specificity of RBPT was little less then STAT. Thus, RBPT was more sensitive than STAT but specificity of both tests was more or less similar. Hence, IELISA was a better serological test as compared to RBPT and STAT and it could be advocated for screening of small ruminants (Table 3 and Fig 2).

In case of goat, the sensitivity of RBPT and STAT was $27.27 \%$ and $18.18 \%$, respectively, considering I-ELISA as a gold standard test while specificity was $97.82 \%$ and $100 \%$, respectively. Thus, sensitivity of RBPT was more than STAT but specificity of RBPT and STAT was somewhat similar. The overall agreement of RBPT and STAT with I-ELISA was $60.00 \%$ and $55.00 \%$, respectively. Hence, I-ELISA was a better serological test as compared to RBPT and STAT and it could be advocated for screening of goats (Table 4 and Fig. 3).

In case of sheep, the sensitivity of RBPT and STAT was $28.95 \%$ and $15.78 \%$, respectively, considering I-ELISA as a gold standard test while specificity was $100 \%$ for both test. Thus, sensitivity of RBPT was more than STAT but specificity of RBPT and STAT was similar. An overall agreement of RBPT and STAT with I-ELISA was $73.00 \%$ and $68.00 \%$, respectively. Hence, I-ELISA was a better serological test as compared to RBPT and STAT and it could be advocated for screening of sheep (Table 5 and Fig. 4). Overall seroprevalence of brucellosis in small ruminants

In the present study, the overall seroprevalence of brucellosis was $13.50 \%$, $8.00 \%$ and $46.50 \%$ in small ruminants by RBPT, STAT and I-ELISA, respectively (Table 1\&2, Fig. 1)

The finding of present study was similar with the finding of Tegeg net al.,(2016)who reported overallseroprevalencewas $13 \%$ with RBPT in small ruminants. Similar result was also reported by Valarmathy et al., (2007) which was $13.80 \%$ by RBPT and $8.28 \%$ by STAT and Shadhu et al., (2015) who also reported the seroprevalence of $11.30 \%$ and $11.10 \%$ by RBPT and STAT, respectively of small ruminants in Banaskantha district. In addition, Kumar et al., (2015) who found 7\% seroprevalence by STAT in animals in and around Junagadh district of Gujarat state. In addition, Din et al., (2013) who reported $13.33 \%, 11.33 \%$ and $9.33 \%$ by RBPT, SPAT and STAT, respectively which was more or less similar to the present study.

\section{Comparative efficacy of serological tests}

Overall, comparison to $46.50 \%$ of seropositivity in I-ELISA, $13.50 \%$ and $8.00 \%$ of the samples were found seropositive by RBPT and STAT, respectively. In goat, comparison to $55.00 \%$ of seropositivity in IELISA, $16.00 \%$ and $10.00 \%$ of the samples were found seropositive by RBPT and STAT, respectively while in sheep comparison to $38.00 \%$ of seropositivity in I-ELISA, $11.00 \%$ and $6.00 \%$ of the samples were found seropositive by RBPT and STAT, respectively. 
Table.1 Overall seroprevalence of brucellosis in small ruminants (sheep and goats)

\begin{tabular}{|l|c|c|c|}
\hline Species & Total number of sera tested & No. of positive sera samples & Percentage (\%) \\
\hline Goats & 100 & 56 & $56.00 \%$ \\
\hline Sheep & 100 & 38 & $38.00 \%$ \\
\hline Total & 200 & 94 & $47.00 \%$ \\
\hline
\end{tabular}

Table.2 Overall sensitivity, specificity and agreement of RBPT and STAT by comparing with IELISA (Gold Standard Test) for detection of Brucella antibodies in goats

\begin{tabular}{|c|c|c|c|c|c|c|c|}
\hline \multicolumn{2}{|c|}{ Serological Test } & \multicolumn{2}{|l|}{ I-ELISA } & \multirow[t]{2}{*}{ Total } & \multirow{2}{*}{$\begin{array}{l}\text { Sensitivity } \\
(\%)\end{array}$} & \multirow{2}{*}{$\begin{array}{l}\text { Specificity } \\
(\%)\end{array}$} & \multirow{2}{*}{$\begin{array}{l}\text { Overall } \\
\text { Agreement } \\
(\%)\end{array}$} \\
\hline & & Positive & Negative & & & & \\
\hline \multirow[t]{3}{*}{ RBPT } & Positive & 15 & 1 & 16 & \multirow[t]{3}{*}{$27.27 \%$} & \multirow[t]{3}{*}{$97.82 \%$} & \multirow[t]{3}{*}{$60.00 \%$} \\
\hline & Negative & 40 & 45 & 85 & & & \\
\hline & Total & 55 & 46 & 100 & & & \\
\hline \multirow[t]{3}{*}{ STAT } & Positive & 10 & 0 & 10 & \multirow[t]{3}{*}{$18.18 \%$} & \multirow[t]{3}{*}{$100 \%$} & \multirow[t]{3}{*}{$55.00 \%$} \\
\hline & Negative & 45 & 45 & 90 & & & \\
\hline & Total & 55 & 45 & 100 & & & \\
\hline
\end{tabular}

Table.3 Overall sensitivity, specificity and agreement of RBPT and STAT by comparing with IELISA (Gold Standard Test) for detection of Brucella antibodies in small ruminants

\begin{tabular}{|c|c|c|c|c|c|c|c|}
\hline \multicolumn{2}{|c|}{ Serological Test } & \multicolumn{2}{|l|}{ I-ELISA } & \multirow[t]{2}{*}{ Total } & \multirow{2}{*}{$\begin{array}{l}\text { Sensitivity } \\
(\%)\end{array}$} & \multirow{2}{*}{$\begin{array}{l}\text { Specificity } \\
(\%)\end{array}$} & \multirow{2}{*}{$\begin{array}{l}\text { Overall } \\
\text { Agreement } \\
(\%)\end{array}$} \\
\hline & & Positive & Negative & & & & \\
\hline \multirow[t]{3}{*}{ RBPT } & Positive & 26 & 1 & 27 & \multirow[t]{3}{*}{$27.95 \%$} & \multirow[t]{3}{*}{$99.06 \%$} & \multirow[t]{3}{*}{$66.00 \%$} \\
\hline & Negative & 67 & 106 & 173 & & & \\
\hline & Total & 93 & 107 & 200 & & & \\
\hline \multirow[t]{3}{*}{ STAT } & Positive & 16 & 0 & 16 & \multirow[t]{3}{*}{$17.20 \%$} & \multirow[t]{3}{*}{$100 \%$} & \multirow[t]{3}{*}{$61.50 \%$} \\
\hline & Negative & 77 & 107 & 184 & & & \\
\hline & Total & 93 & 107 & 200 & & & \\
\hline
\end{tabular}


Table.4 Overall sensitivity, specificity and agreement of RBPT and STAT by comparing with IELISA (Gold Standard Test) for detection of Brucella antibodies in sheep

\begin{tabular}{|c|c|c|c|c|c|c|c|}
\hline \multicolumn{2}{|c|}{ Serological Test } & \multicolumn{2}{|l|}{ I-ELISA } & \multirow[t]{2}{*}{ Total } & \multirow{2}{*}{$\begin{array}{l}\text { Sensitivity } \\
(\%)\end{array}$} & \multirow{2}{*}{$\begin{array}{l}\text { Specificity } \\
(\%)\end{array}$} & \multirow{2}{*}{$\begin{array}{l}\text { Overall } \\
\text { Agreement } \\
(\%)\end{array}$} \\
\hline & & Positive & Negative & & & & \\
\hline \multirow[t]{3}{*}{ RBPT } & Positive & 11 & 0 & 11 & \multirow[t]{3}{*}{$28.95 \%$} & \multirow[t]{3}{*}{$100 \%$} & \multirow[t]{3}{*}{$73.00 \%$} \\
\hline & Negative & 27 & 62 & 89 & & & \\
\hline & Total & 38 & 62 & 100 & & & \\
\hline \multirow[t]{3}{*}{ STAT } & Positive & 6 & 0 & 6 & \multirow[t]{3}{*}{$15.78 \%$} & \multirow[t]{3}{*}{$100 \%$} & \multirow[t]{3}{*}{$68.00 \%$} \\
\hline & Negative & 32 & 62 & 94 & & & \\
\hline & Total & 38 & 62 & 100 & & & \\
\hline
\end{tabular}

Figure.1 Overall test wise seroprevalence of brucellosis in small ruminants (sheep and goats)

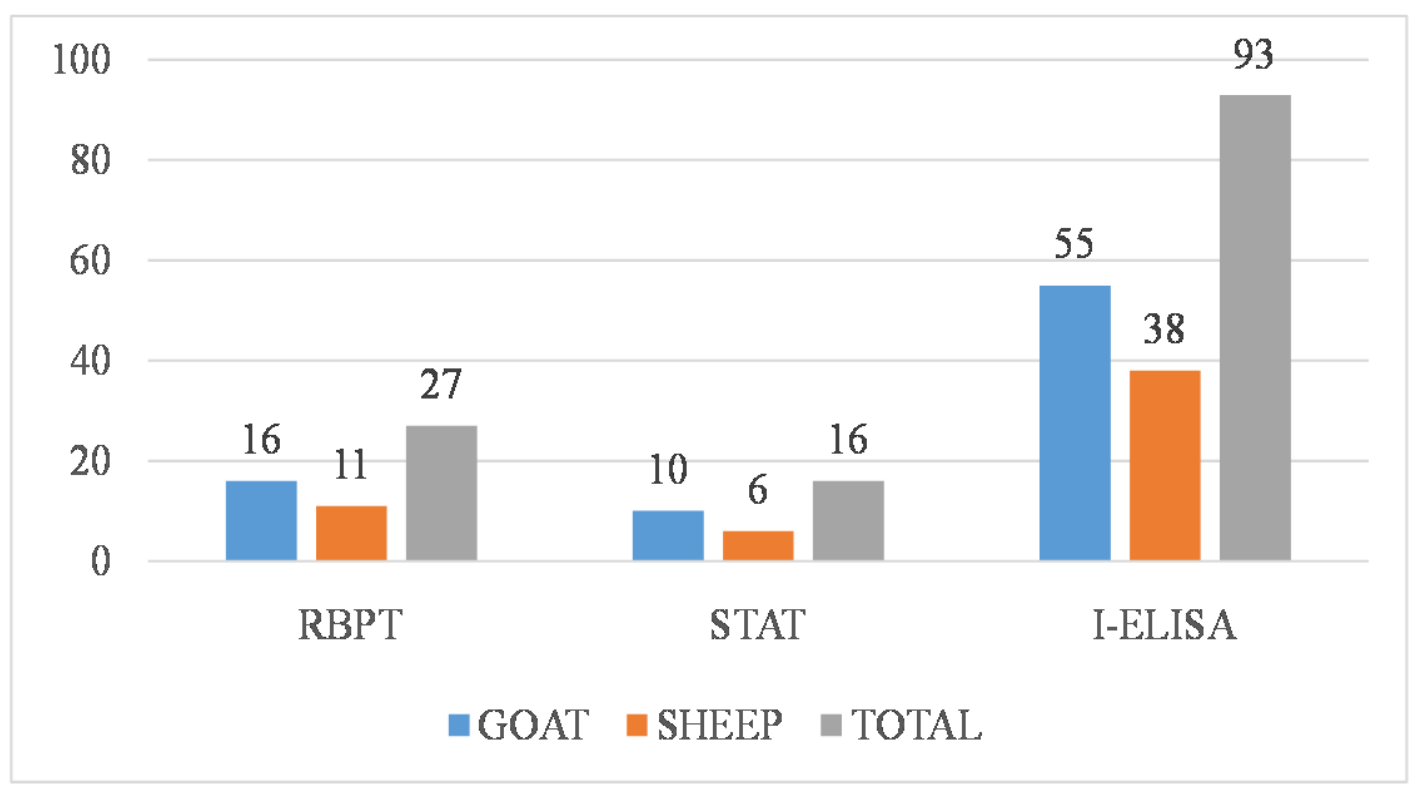


Figure.2 Overall sensitivity, specificity and agreement of RBPT and STAT by comparing with I-ELISA

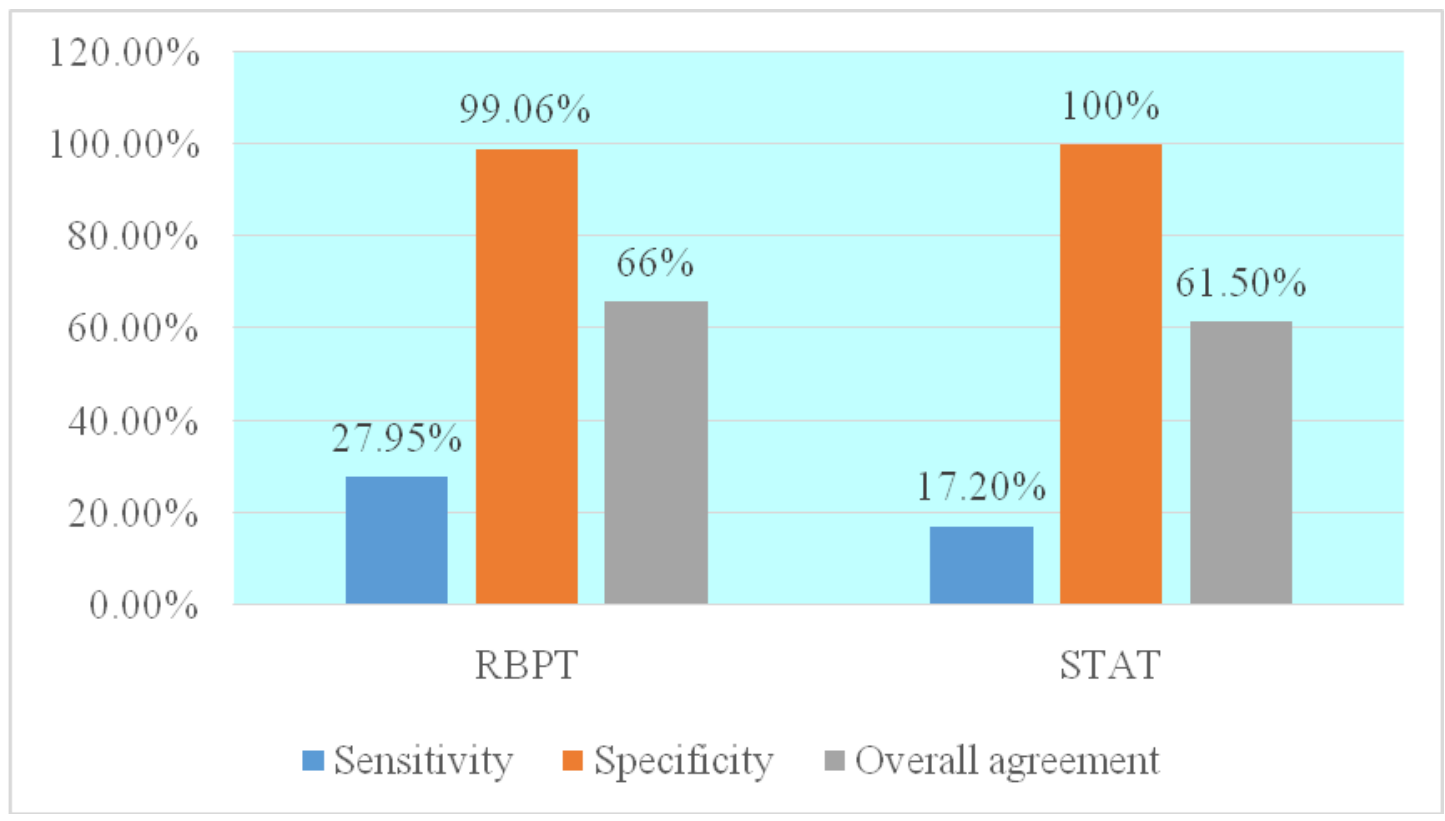

Figure.3 Overall sensitivity, specificity and agreement of RBPT and STAT by comparing with IELISA (gold standard test) for detection of Brucella antibodies in goats

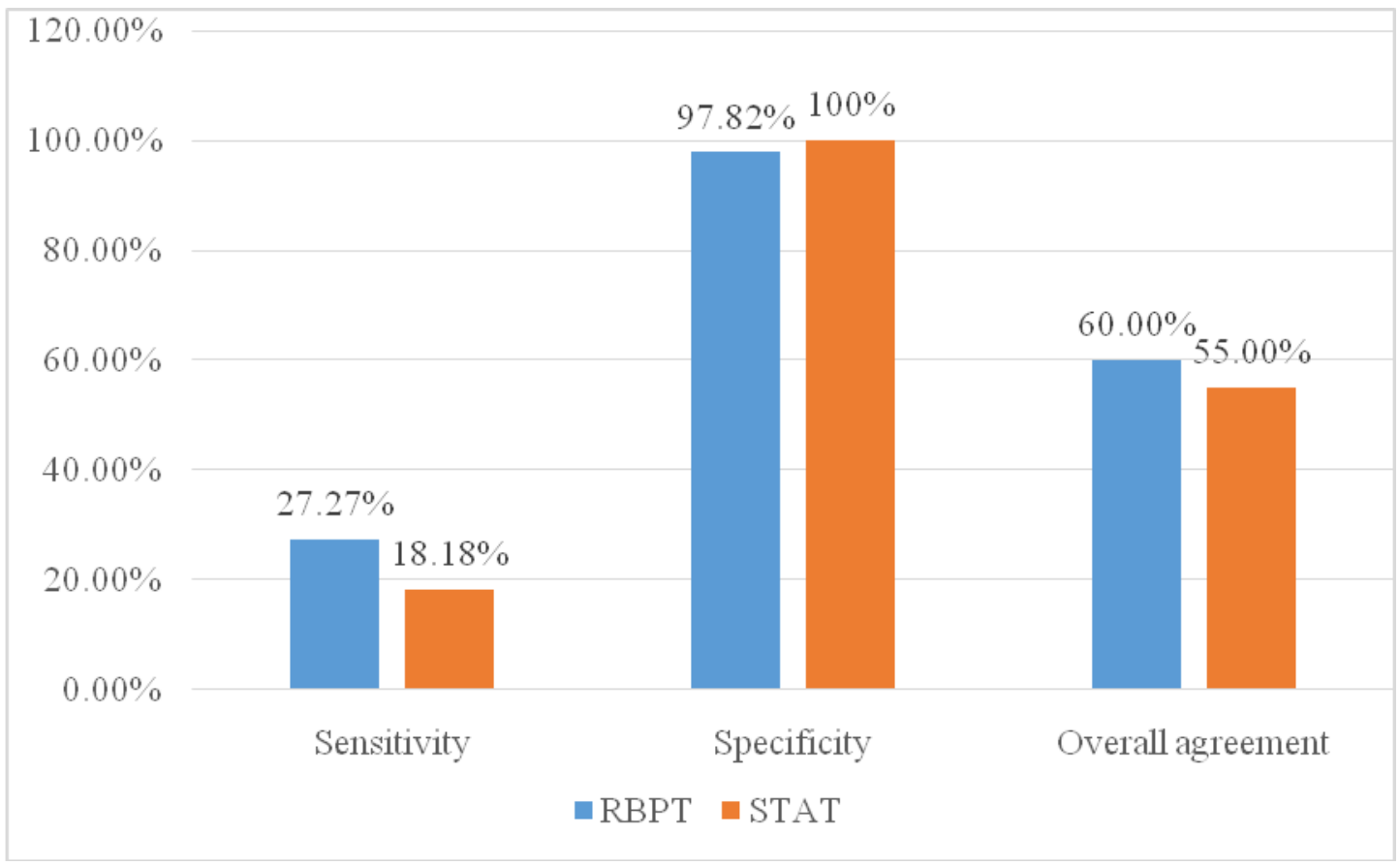


Figure.4 Overall sensitivity, specificity and agreement of RBPT and STAT by comparing with IELISA (gold standard test) for detection of Brucella antibodies in sheep

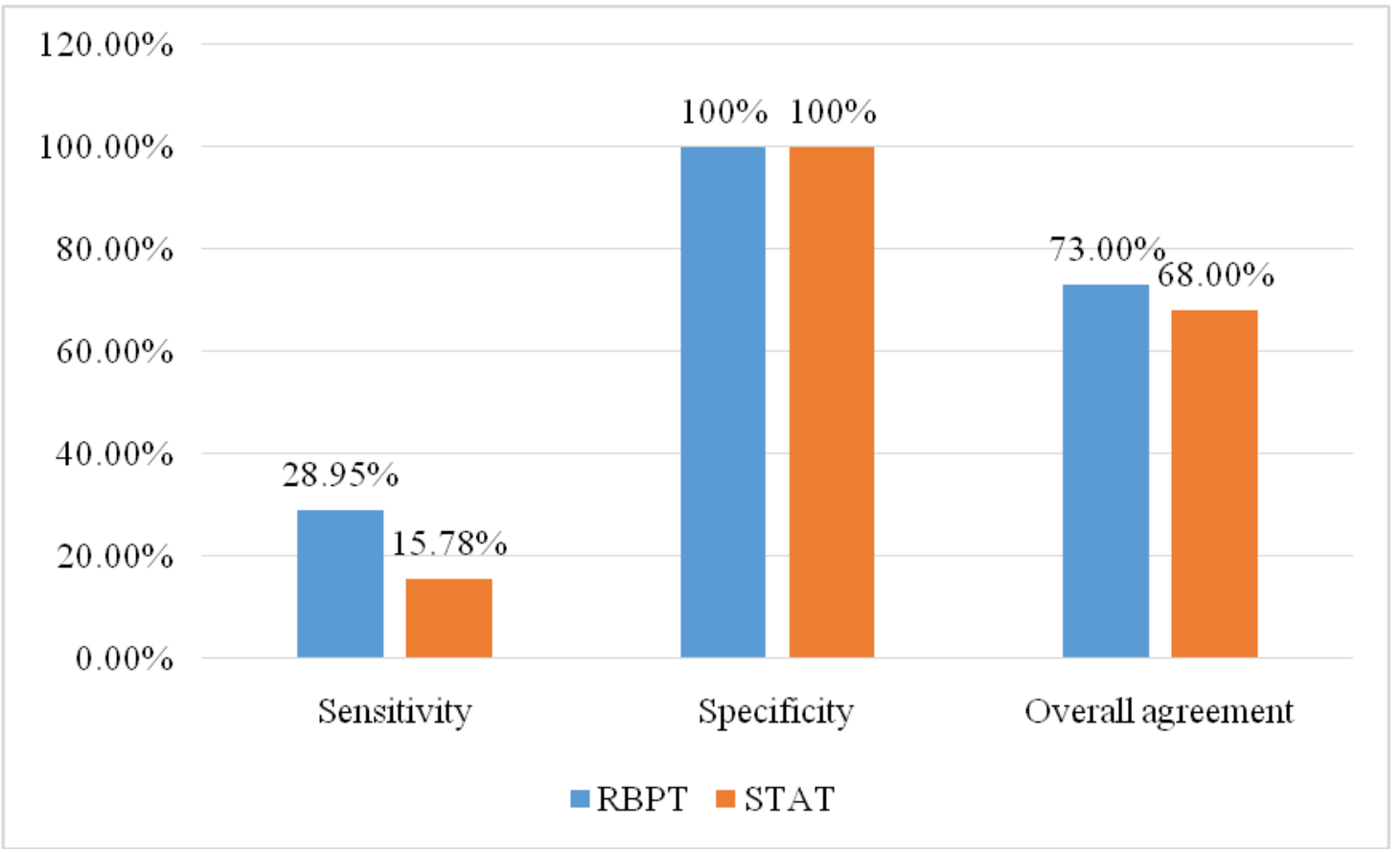

Table No. 2 Detection of Brucella antibodies by RBPT among goats and Sheep

\begin{tabular}{|l|l|l|l|l|}
\hline \multirow{2}{*}{ Species } & \multirow{2}{*}{ Total number of sera tested } & \multicolumn{3}{|l|}{ Various serological methods } \\
\cline { 3 - 5 } & & RBPT & STAT & I-ELISA \\
\hline Goats & 100 & $16(16.00 \%)$ & $10(10.00 \%)$ & $55(55.00 \%)$ \\
\hline Sheep & 100 & $11(11.00 \%)$ & $6(6.00 \%)$ & $38(38.00 \%)$ \\
\hline Total & 200 & $27(13.50 \%)$ & $16(8.00 \%)$ & $93(46.50 \%)$ \\
\hline
\end{tabular}

In comparison to the present study similar seroprevalence was obtained by Din et al., (2013) who found (11.33\%) and (7.66\%) with RBPT and STAT, respectively in goats, similarly, Kotadiya, (2012) who found higher seropositivity of $11.38 \%$ by RBPT as compared to $9.44 \%$ by STAT in sheep. In addition Sonawaneet al., (2011) also observed higher seroprevalence of $15.60 \%$ by I-ELISA as compared to $5.92 \%$ by RBPT in sheep and goat from Rajasthan.

In contrast, Rahman et al., (2011) in goats and sheep who found highest seroprevalence of brucellosis by RBPT followed by STAT and I-ELISA. Shome et al., (2006) in sheep and goats who found lower seropositivity of $7.36 \%$ by I-ELISA as compared to $9.95 \%$ by RBPT from Rajasthan, Gujarat and Karnataka. These variations may be due to the ability of each test to detect different antibody classes. The variation results of different tests could be because of the various factors such as stage of infection, presence of false positive or negative animals and crossreacting organism beside many more.

\section{Comparison of I-ELISA as compare to RBPT and STAT}

Overall sensitivity, specificity and agreement of RBPT and STAT by comparing with I- 
ELISA (Gold Standard Test) for detection of Brucella antibodies in small ruminants

Overall the sensitivity of RBPT and STAT was $27.95 \%$ and $17.20 \%$, respectively, considering I-ELISA as a gold standard test while specificity was $99.06 \%$ and $100 \%$, respectively. An overall agreement of RBPT and STAT with I-ELISA was $66.00 \%$ and $61.50 \%$, respectively (Table 3 and Figure 2).

Similar results was obtained by Tayshete, (2001) who found specificity of RBPT and STAT was $100 \%$ but in contrast to present study sensitivity of RBPT and STAT was $71.42 \%$ which was higher to present study, considering I-ELISA as a gold standard test in small ruminants. In addition Al-Gardia et al., (2011) who noted similar the specificity of commercial RBPT was $99.06 \%$ but in contrast to present study sensitivity of RBPT was $89.04 \%$ which was higher than present study.

In contrast, Coelho et al., (2008) who found higher sensitivity $97.6 \%$ and lower specificity $77.6 \%$ values of RBT in small-ruminant. Similarly Abdel-Khalek et al., (2012) who recorded higher sensitivity $92.9 \%$ for RBT and $90.7 \%$ for TAT while lower specificity $83 \%$ for RBT and $71.4 \%$ for TAT.

Overall sensitivity, specificity and agreement of RBPT and STAT by comparing with IELISA for detection of Brucella antibodies in goats

In case of goat, the sensitivity of RBPT and STAT was $27.27 \%$ and $18.18 \%$, respectively, considering I-ELISA as a gold standard test while specificity was $97.82 \%$ and $100 \%$, respectively. The overall agreement of RBPT and STAT with I-ELISA was $60.00 \%$ and $55.00 \%$, respectively (Table 4 and Fig.3)

Barbudhe et al., (1994) obtained lower the relative sensitivity and similar specificity to be of $42.85 \%$ and $100.00 \%$ for RBPT, respectively and lower the relative sensitivity and relative similar specificity to be of $28.57 \%$ and $94.17 \%$ for STAT in goats when CFT was considered as gold standard test which was somewhat similar with present finding.

Sharma et al., (2006) recorded the sensitivity $(67.85 \%)$ which was higher than present study and specificity $(99.51 \%)$ which was similar to present study of RBPT in goat of Mehsana and Patan. district of Gujarat when compared with dot-ELISA. Similarly Ekgatat et al., (2010) who found higher diagnostic sensitivity (99.2\%) which was higher than present study and diagnostic specificity $(100 \%)$ which was similar to present study of $\mathrm{RBT}$ in goat.

In addition Reddy et al., (2014) found higher relative sensitivity $(54.16 \%)$ of RBPT and higher relative sensitivity $(66.66 \%)$ of STAT while similar specificity $(100 \%)$ for both tests, considering I-ELISA as a gold standard test in goat of the Karnataka.

Overall sensitivity, specificity and agreement of RBPT and STAT by comparing with IELISA for detection of Brucella antibodies in sheep

In case of sheep, the sensitivity of RBPT and STAT was $28.95 \%$ and $15.78 \%$, respectively, considering I-ELISA as a gold standard test while specificity was $100 \%$ for both test. Thus, sensitivity of RBPT was more than STAT but specificity of RBPT and STAT was similar. An overall agreement of RBPT and STAT with I-ELISA was $73.00 \%$ and $68.00 \%$, respectively (Table 5 and Fig. 4).

Hoverer, Kotadiya, (2012) who recorded higher the sensitivity of RBPT $(65.83 \%)$ and STAT $(62.02 \%)$ while similar the specificity $(100 \%)$ for both the tests, considering I- 
ELISA as a gold standard test in sheep although found similar results that RBPT was more sensitive than STAT but specificity was similar for both tests.

In contrast, Kotadiya, (2012) in sheep, who found overall agreement of RBPT and STAT with I-ELISA were $93.78 \%$ and $91.25 \%$, respectively which was relative higher than present study. Similarly, Shadhu et al., (2015) who found overall agreement of RBPT and STAT with I-ELISA was $92.50 \%$ and $92.30 \%$ in small ruminants which was higher than present study.

However in view of cost consideration, feasibility and reliability as field diagnostic test RBPT has been found to be much cheaper, easier and convenient to perform than ELISA.

\section{Acknowledgement}

The authors are highly thankful to the Dean, College of Veterinary science and A.H. Anand for financial assistance and research facilities to conduct this research work and also thankful to Dr. Snehal Patel Deputy director of animal husbandry of Annand districtfor kind support.

\section{References}

Abdel-Khalek, M., Ramadan, K., Hazem, S., and Khairy, E. 2012. Evaluation of immunochromatographic assay for serodiagnosis of Brucella among cattle, sheep and goats in Egypt. Global Vet., 8: 511-518.

Al-Garadi, M.A., Khairani-Bejo, S., Zunita, Z. and Omar, A.R. 2011. Detection of Brucella melitensis in blood samples collected from goats. J. Animal and Vet. Adv., 10(11): 1437-1444.

Barbuddhe, S.B., Yadava, V.K. and Singh, D.K. 1994. Detection of $\operatorname{IgM}$ and IgG antibodies against Brucella by dot-ELISA in humans. The J. Communicable Dis., 26(1): $1-5$.

Din, A.M.U., Khan, S.A., Ahmad, I., Rind, R., Hussain, T., Shahid, M. and Ahmed, S. 2013. A study on the seroprevalence of brucellosis in human and goat populations of district Bhimber, Azad Jammu and Kashmir. J. Anim. Plant Sci., 23(1): 113118.

Ekgatat, M., Kanitpun, R., Kunchit, P., Arampong, W., Raksajit, S., Thammasart, S. and Wongkasemjit, S. 2010. Comparison of serological tests for antibody detection against Brucella melitensis infection in goats. Kasetsart Veterinarians, 20(1): 19-26.

Kotadiya, A.J. 2012. Serological, cultural and molecular detection of Brucella infection of sheep in Gujarat. M. V. Sc. thesis submitted to SardarkrushinagarDantiwada Agriculture University, Sardarkrushinagar, Gujarat.

Kumar, A.V., Srikanth, N.R., Naresh, G. and Vidya, B. 2015. Assessment and comparison of serum biochemical parameters of Brucella infected and healthy ewes. J. Livestock Sci., 6: 100103.

MacMillan, A.A. 1990. Conventional serological tests. Animal brucellosis, 206: 153-197.

Mathur, T.N. 1967. Isolation of Brucella abortusfrom goats and sheep in the Punjab. Indian J. Vet. Sci., 37: 277-286.

McDermott, J.J. and Arimi, S.M. 2002. Brucellosis in sub-Saharan Africa: epidemiology, control and impact. Vet. Microbiol., 90(1): 111-134.

Pal, M. 2007. Zoonoses. (2nd ed.) Satyan Publishers, Jaipur, India. pp. 98-99.

Polding, J.B. 1942. Brucellosis in India. Ind. J. Vet. Sci., 13: 27-34.

Radostits, O.M., Gay, C.C., Hinchcliff, K.W. and Constable, P.D. (Eds.). 2006. Veterinary Medicine: A textbook of the diseases of cattle, horses, sheep, pigs and goats. Elsevier Health Sciences.

Rahman, M.S., Faruk, M.O., Her, M., Kim, J.Y., Kang, S. and Jung, S.C. 2011. 
Prevalence of brucellosis in ruminants in Bangladesh. Veterinarni Medicina, 56(8): 379-385.

Raju, S., Kolhe, R.P., Raut, C., Shinde, S.V. and Zade, N.N. 2004. Seroepizootological studies on brucellosis in goat and sheep. J. Vet. Public Health, 2(1/2):1-6.

Reddy, D.A., Kumari, G., Rajagunalan, S., Singh, D.K., Kumar, A. and Kumar, P. 2014. Seroprevalence of caprine brucellosis in Karnataka. Vet. World. 7(3): 182-188.

Renukaradhya, G.J., Isloor, S. and Rajasekhar, M. 2002. Epidemiology, zoonotic aspects, vaccination and control/eradication of brucellosis in India. Vet. Microbiol., 90(1): 183-195

Sadhu, D.B., Panchasara, H.H., Chauhan, H.C., Sutariya, D. R., Parmar, V. L. and Prajapati, H. B. 2015. Seroprevalence and comparison of different serological tests for brucellosis detection in small ruminants. Vet. World, 8(5): 561.

Sharma, V.K., Savalia, C.V., Selvam, D.T. and Darekar, S. D. 2006. Seroprevalence of caprine and ovine brucellosis in Mehsana and Patan districts of Gujarat. Intas Polivet, 7(2): 316-318.

Shome, R., Shome, B.R., Deivanai, M., Desai, G.S., Patil, S.S., Bhure, S.K. and Prabhudas, K. 2006. Seroprevalence of brucellosis in small ruminants. Indian $J$. Comp. Microbiol. Immunol. Infect. Dis., 27(1): 13-15.

Singh, S.V., Chaubey, K.K., Gupta, S., Gupta, V.K., Agrawal, N.D. and Kumar, N.
2013. Co-infection of Mycobacterium avium subspecies paratuberculosisand Brucella melitensis in a sirohi breed goats in India. Adv. Anim. Vet. Ci., 1(6): 188190.

Sonawane, G.G., Tripathi, S., and Dubey, S.C. 2011. Sero-incidence of brucellosis in small ruminants of semiarid Rajasthan. Indian J. Animal Sci., 81(4): 327-29.

Tayshete, S.R. 2001. Seroprevalence of brucellosis in North Gujarat. (M. V. Sc. thesis submitted to $\mathrm{S}$. D. A. University, S. K. Nagar, Gujarat).

Tegegn, A.H., Feleke, A., Adugna, W. and Melaku, S.K. 2016. Small ruminant brucellosis and public health awareness in two districts of Afar Region, Ethiopia. $J$. Veterinar. Sci. Technol., 7(335): 2.

Thavamathi, A. 2006. Seroepidemiology of Caprine Brucellosis and Evaluation of Recombinant omp28 as a diagnostic antigen. Thesis, M. V. Sc (Epidemiology) submitted to Deemed University, Indian Veterinary Research Institute, Izatnagar, UP.

Valarmathy, K., Kumar, M., Singh, J.L. and Ananda, B.V. 2007. Seroepidemiological study of brucellosis in sheep and goats in Uttarakhand. J. Vet. Public Health, 5(1): 45-47.

WHO. 2009. Integrated Control Of Neglected Zoonotic Diseases In Africa: Applying The "One Health Concept". WHO Document Production Services, Geneva, Switzerland. Epidemiology Records. 84(17): 147-148.

\section{How to cite this article:}

Padher, R.R., J.B. Nayak, M.N. Brahmbhatt and Mathakiya, R.A. 2017. Comparative Sensitivity and Specificity of VariousSerological Tests for Detection of Brucellosis in Small Ruminants. Int.J.Curr.Microbiol.App.Sci. 6(5): 2090-2099. doi: https://doi.org/10.20546/ijcmas.2017.605.233 